Couples' Perceptual Agreement Regarding Their Relationship

Mohsen Fouladi

\author{
Alan Reifman \\ C. Rebecca Oldham \\ Jayla Head
}

Emma Willis-Grossmann

Sylvia Niehuis 


\begin{abstract}
We introduce an instrument assessing the unique niche of romantic partners feeling they share the same memories and feelings about their relationship: the Shared Reality regarding one's Relationship (SRR) scale. Existing instruments are less specific, assessing partners' sense of agreement not only about their relationship, but topics outside of it (e.g., whether they share an opinion about a particular movie). We collected cross-sectional data on 656 romantically partnered individuals (from dating to marriage), testing alpha (equal item-weighting) and composite (non-equal weighting) reliability, and convergent, concurrent, criterion-related, and discriminant validity (two types). We also conducted a test-retest reliability study with a roughly two-three week interval between assessments $(N=58$ individuals $)$. The SRR scale exhibited satisfactory psychometric properties in these areas.
\end{abstract}




\section{Couples' Perceptual Agreement Regarding Their Relationship}

Successful romantic relationships require a transformation of two people from strangers, living in separate worlds, to partners with redefined identities and a sense of shared reality (Berger \& Kellner, 1964). Echterhoff, Kopietz, and Higgins (2017) define shared reality as a "motivated process to experience a commonality of inner state about a target" (p. 479). More precisely, Echterhoff, Higgins, and Levine (2009) specify four criteria for whether individuals experience a shared reality: (1) one or both persons believe themselves to be experiencing the same inner state (emotion, attitude, etc.) as the other person; (2) the inner state refers to a given attitude object (i.e., the target of one's opinion, such as a particular movie); (3) striving for shared reality stems either from epistemic (understanding, knowledge) or relational (interpersonal connection) motivation; and (4) one "perceive[s] the commonality to have been, in fact, established" (p. 500), with no overt evidence contradicting one's perception of a shared inner state. Echterhoff and colleagues' shared-reality construct is similar to what Pinel, Bernecker, and Rampy (2015) call "I-sharing," which they define as "the belief or sensation that one has an identical subjective experience with at least one other person" (p. 60). Note that objective congruence in how two people perceive or recall a given event or experience is not strictly a part of shared reality as conceptualized by Echterhoff et al. (2009) and Pinel et al. (2015); however, it can bolster a subjective sense of shared reality. Also, partners may possess a sense of shared reality about events and attitude objects both inside the relationship (e.g., do partners believe each other to hold similar views on whether and when to have children?) and outside the relationship (e.g., whether they believe each other to like a certain restaurant). The current article presents the development and psychometric testing of a new measure of shared 
reality regarding one's relationship and does not pertain to attitude objects outside the relationship.

\section{Importance of Shared Reality to Relationships}

Research suggests that partners' failure to converge upon matched definitions and a shared sense of reality likely threatens their relationship (Rossignac-Milon \& Higgins, 2018), unless partners' disagreements concerned trivial topics. Thus, it is crucial for partners to establish a sense of shared reality on their most important issues early in their relationship, to promote the development of intimacy, interdependence, and satisfaction; prevent romantic disillusionment; and increase the long-term success of their relationship (Berger \& Luckmann, 1967; Chadiha, Veroff, \& Leber, 1998; Niehuis, Reifman, \& Lee, 2015; Rossignac-Milon \& Higgins, 2018; Wilson \& Huston, 2013). Disillusionment is "a perceived change for the worse in relationships" (Niehuis et al., 2015, p. 957), relative to the (often lofty) expectations one holds based on idealization earlier in the relationship (see also Niehuis, Lee, Reifman, Swenson, \& Hunsaker, 2011).

Until recently, little research had applied notions of shared reality to romantic relationships, likely for lack of a suitable measure. Two measurement instruments are now available, one already existing and the other to be introduced in the present manuscript. The first, developed by Rossignac-Milon, Bolger, and Higgins (2016) measures romantic partners’ perceived shared reality, leaving the object or target of partners' attitudes or perceptions general (e.g., "We frequently think of things at the exact same time," "We are more certain of the way we perceive things when we are together;" italics added). The second one, which we term the "Shared Reality regarding one's Relationship scale (SRR)," is the one we introduce here. Our instrument focuses specifically on partners' perception of shared reality regarding the 
relationship itself. It contains items such as "My partner and I agree on what stage of our relationship we are in right now" and "Based on my partner's behaviors, I know we share the same relationship values." Both of these instruments are grounded in Echterhoff et al.'s (2009) conceptualization, and each has its place in studying couples' perceived shared reality. Whereas Rossignac-Milon and colleagues' (2016) instrument is optimal when researchers are interested in couples' general sense of shared reality (applying to attitude objects inside and outside the relationship), ours is optimal when researchers are interested specifically in couples' sense of shared reality only about their relationship. As we discuss below, there are important reasons why researchers might want to focus on shared-reality perceptions about one's relationship, per se. Another concept, existential connection (Pinel et al., 2015), when modified to refer to one's romantic partner instead of humanity at large, may also conceptually overlap with both couples' general shared reality and shared reality regarding one's relationship. We elaborate upon existential connection below.

\section{Review of Shared-Reality Literature}

Prior to Rossignac-Milon et al.'s (2016) and our attempt to create a measure of romantic partners' perceived shared reality, studies mainly inferred participants' sense of shared reality from behavior in certain situations. Boothby, Clark, and Bargh (2014) conducted two studies in which participants rated the taste of a chocolate candy in the presence of a confederate (without communication) who either worked on the same task or a different task (e.g., judging art). The mere presence of someone working on the same task not only polarized participants' ratings of the chocolates, but also, in one of the studies, raised participants' ratings of how much they felt "on the same wavelength" with the confederate. Boothby et al. suggested that shared experiences even without communication may foster a sense of thinking together. Gomillion, Gabriel, 
Kawakami, and Young (2017), for instance, found couples' shared media usage (controlling for overall time spent together) positively predicted their relationship quality, possibly because joint media consumption promotes a sense of sharing. Finally, a paradigm used by Echterhoff, Higgins and colleagues in several studies (Echterhoff et al., 2009) has shown the ability to induce a shared mindset between a focal participant and a novel group (by giving the participant a goal for what to convey to the group), so that the participant's post-test recollections are a closer match to the group's impressions than to the original stimulus materials.

\section{Value of Assessing Shared Reality Regarding One's Relationship}

Rossignac-Milon and Higgins (2018) contend that "jointly satisfying epistemic needs... bonds partners at various relationship phases" (p. 66). In fact, they argue, the discovery of shared feelings - which can pertain to anything such as art, entertainment, or sociopolitical views - may be what launches a relationship in the first place. Furthermore, recent studies suggest that being in sync about the relationship itself may enhance partners' feelings toward each other. A longitudinal study of objective congruence, couched in terms of the disillusionment model, revealed a benefit for marriages wherein spouses agreed with one another on their versions of important courtship events (Wilson \& Huston, 2013). In newlywed couples followed for 14 years, Wilson and Huston found lack of partners' consensus on how their marriage likelihood progressed during courtship was a strongly significant predictor of divorce. Importantly, in obtaining each partner's marriage-likelihood estimates, the researchers asked each partner to take into account the other partner's perspective, as well as his or her own. Niehuis, Ogolsky, Reifman, Oldham, and Ireland (2018) extended this finding in a pair of longitudinal studies, finding in path-analysis models that partners' congruence in courtship recollections predicted more frequent verbal connectedness markers in their courtship interviews ("we" and affiliation- 
related references, e.g., friend, ally). Verbal connectedness markers, in turn, were negatively associated with disillusionment.

Studies focusing on courtship memories other than marriage-probability recollections have found similar results. In a cross-sectional study, Alea and Vick (2010) instructed married individuals to recall "either the first time you met your spouse, or when you saw the first glimmer of or potential for lasting love" (p. 734). The instruction also characterized the requested memory as "probably the memory that your spouse would share as their first encounter experience with you" (p. 735). This last component of the instruction fulfills Echterhoff and colleagues' (2009) criteria for shared reality (i.e., perceived sharing of an inner state, about the relationship, inspired by the relationship, and no contradiction). Alea and Vick found qualities of the shared memory, such as vividness and intensity, to be positively associated with marital satisfaction. In a similar vein, Philippe, Koestner, and Lekes (2013) asked university students in dating relationships to describe "a specific, significant personal memory of an experience that they had within their current couple relationship" (p. 167). Results over multiple studies by Philippe and colleagues showed that the more participants rated these events as fulfilling needs for autonomy, competence, and relatedness, the greater their relationship satisfaction. Fulfillment of these needs has been linked to lower existential isolation, which could be considered akin to greater shared reality (Pinel et al., 2015). In sum, these studies each show some association between recollection of relationship-specific events (in most cases, relative to a partner's recollection) and relationship satisfaction, disillusionment, and/or stability.

None of these studies (Alea \& Vick, 2010; Niehuis et al., 2018; Philippe et al., 2013; Wilson \& Huston, 2013) directly assessed the extent of partners' perceived agreement on relationship occurrences. They did, however, touch upon memories of particular relationship 
events (which, as Alea and Vick instructed participants, should be a memory their spouse would share), actual agreement, and linkages of the memories to linguistic or need-fulfillment signs of shared experience - aspects we would consider related to couples' sense of shared reality about their relationships. Because there was no specific measure to be used in these studies to assess perceived shared reality about relationship-specific events, such a construct could not be studied precisely. Creation of a perceived shared reality measure about one's relationship will, therefore, sharpen our findings about partners' relationship-specific sense of shared reality. Further, a brief, easy-to-administer assessment of perceived shared reality would be less laborious for researchers than alternative measures such as courtship graphs (Wilson \& Huston, 2013) or couple interviews (Holmberg, Orbuch, \& Veroff, 2004).

\section{Construction of the Shared Reality Regarding One's Relationship Scale}

We conducted two studies to establish several forms of validity and reliability for our new measure. Our approaches to doing so are described in the following subsections. Table 1 presents an overview of measures used in one or both of our studies to establish various forms of validity.

Concurrent and convergent validity. ${ }^{1}$ Rossignac-Milon et al.'s (2016) measure, which we refer to as assessing couples' general shared reality, leaves the object or target of partners' shared perception open. Rossignac-Milon and colleagues' measure still is closely linked to our own, both being grounded in Echterhoff and colleagues' (2009) framework. According, we used couples' general shared reality in our scale-development studies to establish concurrent validity. We would expect a relatively large positive correlation between our new SRR measure and the couples' general shared-reality one, but not one so large as to suggest the measures were identical. A second construct conceptually similar enough to shared reality to use for concurrent- 
validity purposes is existential connection (Pinel et al., 2015), which is the reverse-scored version of existential isolation (Pinel, Long, Murdoch, \& Helm, 2017). Existential isolation is the sense of feeling "as though nobody else shares [one's] experience or could come close to understanding it" (Pinel et al., 2017, p. 55). Framing existential isolation (in reverse) as existential connection, and modifying the items to refer not to humanity at large, as conceptualized by Pinel and colleagues, but instead to one's romantic partner, suggests a likely kindred measure with the SRR. Even when modified in this way, however, the existentialconnection items would still, like Rossignac-Milon et al.'s (2016) measure of couples' general shared reality, be tapping partners' perceptions of how they respond to all attitude objects, inside and outside the relationship (sample existential-connection items are "My partner has the same take or perspective on things that I do," "My partner and I react to things in our environment in the same way"). Accordingly, we would expect a large positive association between the Rossignac-Milon et al. measure and the modified existential-connection measure, because both pertain to general topics. We would also expect the modified existential-connection measure to exhibit a moderate positive association with the SRR, as the latter pertains to relationshipspecific topics.

Other constructs are better characterized as being conducive to a sense of shared reality rather than being directly similar to it, namely partners' propensities toward self-disclosure, responsiveness, empathic concern, and perspective-taking. Accordingly, these variables were used to test the SRR's convergent validity. Although, as noted above, being in a co-actor's presence without explicit communication can potentially create an initial sense of shared reality with the other person (Boothby et al., 2014), it is almost certain that direct communication including in the form of self-disclosure - is needed to maximize romantic partners' sense of 
shared reality. Rossignac-Milon and Higgins (2018), citing Berger and Kellner (1964), note that "communication is the primary mechanism underlying reality co-construction" and that "One central communication practice contributing to closeness is the gradual increase in the depth and breadth of self-disclosure" (both quotes from p. 67). The construct of interpersonal responsiveness, representing one's perception of how well another person knows, understands, respects, values, and likes oneself, has been posited to promote mutual self-disclosure (Reis, Maniaci, Caprariello, Eastwick, \& Finkel, 2011). Hence, we also examine responsiveness. Echterhoff and colleagues (2009) see empathy and perspective-taking also as contributors to a sense of shared reality, but not as isomorphic with it. These authors contend that perspectivetaking allows an observer to see an issue in the same way as another person (i.e., a common view of what the situation is "about"), but does not require a common inner state. Thus, selfdisclosure, responsiveness, empathic concern, and perspective-taking should correlate positively with our SRR measure (adding to its convergent validity), although not as strongly as would the couples' general shared-reality measure (Rossignac-Milon et al., 2016) and Pinel et al.'s (2017) measure of existential connection.

One final measure we examine for possible convergent validity with the SRR is the Inclusion of Other in the Self (IOS) pictorial closeness display (Aron, Aron, \& Smollan, 1992). Participants view seven pairs of circles (with circles labeled "Self" and "Other") in displays ranging from completely non-overlapping to nearly completely overlapping circles. Greater overlap represents the perceiver's greater sense of closeness to the partner. The SRR and IOS would likely correlate moderately positively, as perceiving oneself and one's partner to be virtually a singular entity may also foster the belief that one thinks the same way as one's partner does about the relationship. All of the aforementioned candidates for convergent validity with the 
SRR were assessed in Study 1 only, except for the IOS (assessed in Studies 1 and 2) and responsiveness (Study 2 alone).

Criterion-related validity. For criterion-related validity, we examined the association of our SRR (as well as the couples' general shared-reality and existential-connection measures) with relationship satisfaction and disillusionment. Both theoretical arguments (Rossignac-Milon \& Higgins, 2018) and empirical findings (Gomillion et al., 2017; Niehuis et al., 2018) described above link shared experience/reality to enhanced relationship quality and lower disillusionment. However, these expected positive correlations would only be moderate, as perceiving shared reality or shared perspectives is not fully identical to relationship quality.

Discriminant validity. We test two forms of discriminant validity. For the traditional form (i.e. that a focal construct should show little to no association with theoretically unrelated constructs), we test for any association between the SRR and the construct of familism (importance of family; Harris et al., 2008; Knight et al., 2010). Although familism taps into close interpersonal relationships, it does not specifically delve into a sense of shared reality with family members and so is a good candidate for examining traditional discriminant validity. Hence, we would expect a correlation close to zero. A second type of discriminant validity pertains to the likely associations among the SRR, couples' general shared-reality, and existential-connection instruments. This kind of discriminant validity applies when two or more constructs clearly have some non-zero correlation, but the researcher seeks to test whether they are so highly correlated as to be redundant with each other (Cheung \& Wang, 2017; Mahmood, Dahlan, Hussin, \& Ahmad, 2018). We examine this latter question using Average Variance Extracted (Cheung \& Wang, 2017) from exploratory Principal Components Analysis (PCA). 
Supplementary analyses. Finally, we conducted three supplementary analyses to probe further the validity, reliability, and generalizability of the SRR. First, although Echterhoff et al. (2009) argue that their conceptualization of shared reality does not involve actual or objective agreement between parties, one might still expect some degree of association between partners' scores on romantic-relationship variables. Accordingly, we examined between-partner correlations, which we see as being somewhat akin to inter-rater reliability. With our SRR, partners within a dyad would not be judging the exact same stimulus (e.g., a job-candidate's videotaped interview) as in traditional inter-rater reliability. However, the two partners' independent perceptions of shared reality may stem from elements of their "dyadic climate" that each of them can perceive. Second, self-disclosure, in addition to possibly showing actor-effects with shared reality (i.e., the two constructs being related in the same person), may also relate to a sense of shared reality via partner effects (i.e., one partner's disclosure strengthens the other partner's sense of shared reality). Such an association might be considered a form of convergent validity. Accordingly, we tested an Actor-Partner Interdependence Model (APIM; Kenny, Kashy, \& Cook, 2006) with these variables. Third, we drew our participants from multiple sources, mainly a university community and Amazon.com's Mechanical Turk (MTurk). We conducted multiple-group modeling to assess the generalizability of results across sources.

\section{Study 1 (Cross-Sectional)}

The goals of Study 1 were to provide initial information on the reliability (alpha, which assumes equal weighting of items, and composite reliability, which does not) and validity (concurrent, convergent, criterion-related, and discriminant) of the SRR. Two forms of discriminant validity were tested, lack of association to a theoretically unrelated construct and lack of total redundancy with theoretically related constructs. 


\section{Methods}

Samples and procedures. Participants consisted of individuals 18 and older who were in romantic relationships ranging from casually dating through married. Following IRB approval, these individuals were recruited (with or without their partners) from a university community via a daily electronic campus-wide announcement "blast" and from the U.S. population via Amazon.com's Mechanical Turk (MTurk) online service. The university announcement system sends a single daily e-mail message featuring a compilation of academic, administrative, cultural-event, and other notices. We ran our announcement weekly (the maximum frequency allowed) during our recruitment periods. MTurk has gained popularity in recent years due to its low price, wide accessibility, and demonstrated reliability of measurement (Buhrmester, Kwang, \& Gosling, 2011). We restricted our MTurk sample to U.S. residents. In addition to MTurk and the university e-mail announcements, small numbers of participants were recruited via in-class announcements, posted flyers, requests from one's romantic partner, word-of-mouth from friends, etc.Our announcement called for persons "currently in a romantic relationship," without specifying a minimum relationship length.

The study sought both partners' participation. If both partners agreed, they were included in our couples' sample ( $N=150$ couples described below). However, in many cases only one partner per couple took part, leading to placement in the individuals' sample $(N=356)$. In the couples' sample and in the individuals' sample, the data were pooled across sources (i.e., university, MTurk, etc.). For each participant, a link (with a unique password) was provided, so participants could access the survey via the Qualtrics online service. Participants were asked to share their password with their partner, so we could identify each couple for dyadic analysis. The notice stated that if both partners in a couple participated, they would be entered into a drawing 
for a pair of $\$ 10$ Amazon gift cards, with odds of 1 in 25 . Demographic comparisons by recruitment source are reported in an online supplement. These sample sizes represent as many participants as we could recruit during the semesters in which we gathered data (respondents who left blank the shared-reality items are not included in the sample sizes reported herein). Figure 1 provides a schematic of the individuals' and couples' samples in Study 1.

Couples' sample. To ensure proper analysis of distinguishable and indistinguishable dyads (Kenny et al., 2006), the couples' dataset was divided into opposite-sex couples $(N=130)$ and same-sex/other-gender-identity couples $(N=20)$. Many participants were recruited by their own partner $(57 \%$ of men and $20 \%$ of women in opposite-sex couples, and $28 \%$ and $33 \%$ of the arbitrarily designated Partners 1 and 2, respectively, in the same-sex/other gender-identity couples). The university announcement system accounted for $29 \%$ of the men, $40 \%$ of the women, $28 \%$ of the Partner-1 designees, and 22\% of the Partner-2 designees, whereas MTurk accounted for $8 \%$ of the men, $12 \%$ of the women, $22 \%$ of the Partner- 1 designees, and $17 \%$ of the Partner-2 designees. Men and women were, of course, equally represented in the oppositesex portion of the couple sample. In the non-heterosexual portion of this dataset, there appeared to be roughly twice as many women as men, although respondents selecting different gender identity (other than male or female) precluded an exact figure. Among opposite-sex couples, the most common relationship statuses were exclusively dating (55\%) and married (22\%); all other categories had fewer than $10 \%$. In the same-sex couples, 35\% were exclusively dating, 15-20\% were casually dating or dating multiple people (depending upon whether we look at Partner 1's or Partner 2's reports), 15-20\% were cohabiting (same issue), and 15\% each married or engaged. The couples' sample had higher percentages of White $(72 \%$ each of men and women among opposite-sex couples; $65 \%$ of participants designated as Partner 1 and 55\% of those designated 
as Partner 2) and Latinx (15\% of men, $16 \%$ of women; $20 \%$ and $35 \%$ of the Partner- 1 and Partner-2 designees) participants than did the individual sample. Participants in the couple sample were younger on average than those in the individual sample, with men roughly 25 years old and women 24 in the opposite-sex portion of the sample, and the arbitrarily designated Partners 1 and 2 each reporting average ages of roughly 23 in the same-sex/other sexual orientation portion. Mean relationship length (averaging over both partners' reports within each couple) in the couples' sample was 42.3 months $(S D=52.8)$ in opposite-sex couples and 24.8 months $(S D=29.0)$ in the same-sex/other sexual orientation couples.

Individuals' sample. Participants in the individuals' sample were recruited predominantly from MTurk (69\%) and our university community (19\%). The remaining 12\% of participants were comprised of small percentages coming from different recruitment methods (e.g., 2.0\% from in-person announcements, 1.7\% from partner requests). Women comprised $71 \%$ of the individuals' sample (one person selected "A different identity" for gender). Most participants in the individual sample (84\%) reported being heterosexual, with $10 \%$ bisexual, $4 \%$ lesbian, and $1 \%$ each for gay males and persons claiming a different identity for sexual orientation. The most common relationship statuses were married (36.2\%), exclusive dating (26.7\%), cohabiting (18.5\%), engaged (9.6\%), and casually dating or dating multiple people (7.9\%). This sample was highly diverse on race-ethnicity (61\% White, 13\% Asian/AsianAmerican, 9\% Latinx, 6.5\% Black/African-American, 4\% multi-ethnic, 3.4\% Native American, $2 \%$ other, and $<1 \%$ Pacific Islander $)$. Participants' average age was just short of 30 years $(\mathrm{M}=$ 29.7, $\mathrm{SD}=9.4)$ and their average relationship length was 72 months $(\mathrm{SD}=87)$.

Measures. Shared reality regarding one's relationship. Based upon Echterhoff et al.'s (2009) conceptualization and criteria, as well as Huston's courtship-graph method of having 
partners tell the chronological story of their relationship (Wilson \& Huston, 2013), we generated an initial set of 18 items for the SRR. Because some of the items applied to attitude objects outside of people's relationships and others harmed alpha reliability, we removed 13 items to yield an internally reliable five-item instrument concentrating on shared reality about respondents' relationships (see Table 2). These items were in the form of statements about the sense of shared reality respondents might feel with their partner about their relationship. Response options ranged from 1 (strongly disagree) to 7 (strongly agree). The SRR yielded high alphas on the whole: .91 for men and .85 for women in the individuals' dataset; and .78 for men and .85 for women in the opposite-sex couples' dataset (the small sample size for the samesex/other sexual orientation couples' dataset led to variation in alphas between .66-.83, depending on whether the standardized/equal-variance or unstandardized solution was consulted, indicating that the items likely had unequal variances in this subsample; IBM Support, 2018).

Couples' general shared reality. Rossignac-Milon and colleagues (2016) developed an eight-item scale (see Table 2) to measure couples' general shared reality. The same seven-point strongly disagree-strongly agree scale as used with the SRR was used with the couples' general shared-reality measure. Alpha levels were high (.91 for men and .89 for women in the individuals' dataset; .72 for men and .85 for women in the opposite-sex couples' dataset; and .79 for Partner 1 and .88 for Partner 2 in the same-sex/other sexual orientation couples' dataset).

Existential connection/isolation. Existential connection/isolation was assessed with Pinel and colleagues' (2017) Existential Isolation Scale. As noted, we reworded this scale's six items to apply to one's romantic partner, rather than people in general. We excluded the item "It makes me feel lonely when my partner doesn't share my perspective and feelings on a given topic," as alpha reliability went up considerably without it. The remaining five items appear in Table 2. 
The same seven-point strongly disagree-strongly agree scale as used with the above measures was used here. Because this measure is being used in concurrent-validity analyses with the SRR and couples' general shared-reality measures (and Pinel et al. used positive wordings for most of their items), we thought it more intuitive to code higher scores as representing greater existential "connection" with other people (a term Pinel et al., 2015, have used), rather than their isolation. Alpha levels were high (.85 for men and .88 for women in the individuals' dataset; .78 for men and .87 for women in the opposite-sex couples' dataset; and .77 for Partner 1 and .82 for Partner 2 in the same-sex/other sexual orientation couples' dataset).

Empathy/perspective-taking. We used two seven-item subscales of the Interpersonal Reactivity Index (IRI; Davis, 1980) to assess Empathic Concerns and Perspective-Taking. We did not use the Fantasy and Personal Distress subscales, as these seemed less directly related to our purposes. A sample Empathic Concern item is: "I am often quite touched by things that I see happen." A sample Perspective-Taking item is: "I try to look at everybody's side of a disagreement before I make a decision." Participants were instructed to rate items on a five-point scale, ranging from 1 (does not describe me well) to 5 (describes me very well). The validity and reliability of the IRI has been documented in several studies (Gilet, Mella, Studer, Gruhn, \& Labouvie-Vief, 2013; Péloquin \& Lafontaine, 2010). In the present study, the alphas for Empathic Concern were high ( .78 for men and .77 for women in the individuals' dataset; .82 for men and .81 for women in the opposite-sex couples' dataset; and .83 for Partner 1 and .80 for Partner 2 in the same-sex/other identity couples' dataset). For Perspective-Taking, reliability was similarly high ( .73 for men and .80 for women in the individuals' dataset; .81 for men and .76 for women in the opposite-sex couples' dataset; and .75 for Partner 1 and .69 for Partner 2 in the same-sex/other sexual orientation couples' dataset). 
Self-disclosure. We used the eight-item Depth subscale of the Level of Relationship Development Scale (Parks \& Floyd, 1996) to assess self-disclosure. We changed the scale's references to "this person" to "my partner" (e.g., "I usually tell my partner exactly how I feel"). A similar seven-point scale to that utilized for many of the aforementioned measures was used as well for self-disclosure, except that higher scores initially denoted strong disagreement. Necessary scoring-reversals were performed so that a higher overall score represented greater disclosure. Alphas for self-disclosure were lower than for other constructs, but still respectable (.70 for men and .75 for women in the individuals' dataset; .67 for men and .79 for women in the opposite-sex couples' dataset; and .66 for Partner 1 and .59 for Partner 2 in the same-sex/other sexual orientation couples' dataset).

Inclusion of other in the self. We used Aron et al.'s (1992) single-item IOS measure, which as described above, asks respondents to characterize one's closeness to one's partner by selecting one pair of circles (labeled "Self" and "Other") from seven possible pairs. Scoring of the selected pair ranged from 1 (least connected) to 7 (most connected).

Relationship satisfaction. Relationship satisfaction was assessed with the 11-item Marital Opinion Questionnaire (MOQ; Huston, McHale, \& Crouter, 1986). We modified the instructions to make the MOQ applicable to non-marital as well as marital relationships, as have other studies (Mashek, Le, Israel, \& Aron, 2011). In response to the question of how they experience their relationship, participants were asked to rate a set of binary antonyms (e.g., "miserable" vs. "enjoyable"), with a score of 1 closest to one adjective and a score of 7 closest to the other. After the necessary reverse-scoring of items, higher scores represent greater relationship satisfaction. Alphas were consistently high (.92 for men and .94 for women in the 
individuals' dataset; .90 for men and .92 for women in the opposite-sex couples' dataset; and .89 for Partner 1 and .93 for Partner 2 in the same-sex/other sexual orientation couples' dataset).

Romantic disillusionment. We used the 21-item Relationship Disillusionment Scale (Niehuis, 2007; Niehuis \& Bartell, 2006; Niehuis et al., 2015) to assess perceptions that one's relationship has not lived up to one's initial expectations and the accompanying negative feelings toward one's partner and relationship. Sample items include: "I'm beginning to see my relationship in a somewhat more negative light" and "I feel no longer quite as positively about my spouse/partner as I once did.” Items are scored from 1 (strongly disagree) to 7 (strongly agree). Alphas were extremely high (.98 for men and .98 for women in the individuals' dataset; .97 for men and .97 for women in the opposite-sex couples' dataset; and .99 for Partner 1 and .96 for Partner 2 in the same-sex/other sexual orientation couples' dataset).

Familism. Attitudes about the importance of family (including extended family) were measured with six familism items, to assess the (traditional) discriminant validity of the SRR. Four familism items came from the Mexican American Cultural Values Scale (Knight et al., 2010): "When it comes to important decisions, the family should ask for advice from close relatives," "It is always important to be united as a family," "It is important to have close relationships with aunts, uncles, grandparents and cousins," and "Parents should be willing to make great sacrifices to make sure their children have a better life." The other two were taken from a Texas Healthy Marriage Initiative survey instrument (Harris et al., 2008): "Marriage is as much about joining families together as it is about being a couple," and "Children are the glue of marriage." Response options ranged from 1 (strongly disagree) to 5 (strongly agree). Alphas were moderately high (.71 for men and .65 for women in the individuals' dataset; .66 for men 
and .66 for women in the opposite-sex couples' dataset; and .77 for Partner 1 and .80 for Partner 2 in the same-sex/other sexual orientation couples' dataset).

\section{Results}

Overview. We present results for two types of reliability pertaining to the SRR scale: alpha and composite (unlike alpha, not based on a model with equal loadings for all items of a construct; Suhartanto, Ruhadi, \& Triyuni, 2016; Widhiarsoa, \& Kožený, 2013). We also present findings for four types of validity of the SRR: concurrent, convergent, criterion-related, and discriminant. Table 2 presents results of an exploratory PCA (with varimax rotation) on the individuals' sample (due to its large size) that simultaneously included items from the SRR and couples' general shared-reality measures and existential connection. Table 3 displays the correlations used for validity analyses among men and women in the individuals' sample, and men and women in the opposite-sex couples' sample. The correlations for each partner in the same-sex/other sexual orientation couples' sample appear in the online supplemental materials. Not only because of the sheer number of correlations, but also because of the widely varying sample sizes (i.e., 356 participants in the individual sample vs. 20 non-heterosexual couples), we focus on general trends in the magnitudes of correlation between any two given variables, rather than statistical significance. In concurrent, convergent, and criterion-related validity analyses, correlations of the SRR with six out of eight other variables (couples' general shared reality, existential connection, self-disclosure, inclusion of other in the self, relationship satisfaction, and romantic disillusionment) were each significant in at least four of the six subsamples, suggesting these findings were unlikely to be due to chance.

Reliability. As shown toward the bottom of Table 2, the SRR, couples' general sharedreality measure, and existential connection measure all exhibited coefficient-alpha and composite 
reliability values in the $.80 \mathrm{~s}$ in the overall individuals' sample (similar to what was reported above by gender and sample). The exploratory PCA yielded three components with eigenvalues above $1(9.19,1.47$, and 1.33). Varimax rotation was implemented. Component 1 , dominated by SRR items, featured only two cross-loadings exceeding .30 (.31 for the "sharing relationship values" item on Component 3 , which was dominated by high loadings for existential connection, and .46 for the "feeling understood" item on Component 2, which was dominated by high loadings for the couples' general shared-reality items). The SRR's homogeneous focus on shared reality regarding the relationship likely contributed to its small amount of cross-loadings. In contrast, in nine instances the couples' general shared-reality items loaded above .30 on factors dominated by the SRR or existential-connection items, and in three instances the existentialconnection items loaded .30 or above on factors dominated by SRR or couples' general sharedreality items.

Concurrent and convergent validity. The primary examination of concurrent validity involved the SRR, the couples' general shared-reality measure, and the existential-connection measure. The SRR correlated highly with the other two instruments across the different samples, with most of the correlations in the .60 s and .70s (Table 3). The couples' general shared-reality and existential-connection measures were correlated with each other, mostly in the $.60 \mathrm{~s}$ and $.70 \mathrm{~s}$. Further evidence for the SRR's convergent validity was its correlations with self-disclosure (all but one ranging from .34 to .73; including correlations reported in the online supplement) and, somewhat more modestly, with inclusion of other in the self (mostly around the $.30 \mathrm{~s}$ to $.40 \mathrm{~s}$ ). Unexpectedly, the SRR showed only modest and inconsistent relations to empathic concern and perspective-taking. Neither the couples' general shared-reality measure nor existential 
connection showed particularly strong associations with empathic concern and perspectivetaking, either.

Further bolstering the concurrent validity of the SRR, couples' general shared-reality, and existential-connection measures are analyses of the average variance extracted (AVE; ratio of systematic variance from the loadings to systematic plus error variance) and composite reliability from factor analyses (Cheung \& Wang, 2017). Cheung and Wang recommend as criteria for convergent (and presumably concurrent) validity that AVE values are at least close to .50 and factor loadings are likewise at least near .50. As shown in Table 2, all SRR, all but one couples' general shared-reality, and all but one existential-connection items loaded at .50 or greater, with the other two loadings at .45 . AVE values were .55 for SRR, .41 for couples' general shared reality, and .48 for existential connection. On the whole, these results largely support the SRR's concurrent validity.

Criterion-related validity. The SRR showed strong criterion-related validity with two relationship-quality measures: relationship satisfaction (correlations mostly in the $.40 \mathrm{~s}$ ) and romantic disillusionment (mostly from the -.40s to the -.70s; see Table 3). The couples' general shared-reality and existential-connection constructs also showed some sizable correlations but, on the whole, did not relate quite as potently to relationship satisfaction and disillusionment. Also, multiple-regression analyses in the individuals' dataset (our largest sample) showed that, controlling for couples' general shared reality and existential connection, SRR remained a significant predictor of relationship satisfaction $(\beta=.18, p=.02)$ and disillusionment $(\beta=-.28$, $p<.001)$. Existential connection likewise predicted satisfaction $(\beta=.26, p<.001)$ and disillusionment $(\beta=-.17, p=.03)$, whereas couples' general shared reality did not significantly 
predict either outcome. These results support our contention that a sense of shared reality about the relationship itself is important for good relationship functioning.

Discriminant validity. We tested traditional discriminant validity (i.e., that a focal construct should have little to no correlation with theoretically unrelated constructs) via correlations between SRR and familism. These correlations were, with a single exception, always small and nonsignificant: $.37(p<.001)$ and .04 , respectively among men and women in the individuals' sample; -.09 and .11 among men and women in the opposite-sex couples' sample; and .05 and .12 among Partner 1 and Partner 2 in the non-heterosexual couples' sample. According to Cheung and Wang (2017), the kind of discriminant validity pertaining to measures' non-redundancy is supported if two constructs' correlation does not significantly exceed .70 . Correlations between the SRR, couples' general shared-reality, and existential-connection measures in the overall individuals' dataset are all around .70, consistent with their having some uniqueness and non-redundancy. Cheung and Wang also cite the classic Fornell and Larcker (1981) standard for discriminant validity, in which the AVE values of two constructs exceed the square of their correlation. The AVE for the SRR of .55 is indeed greater than the square of the SRR-couples' general shared reality and SRR-existential connection correlations (Table 2).

Supplemental Analyses. First, as noted above, we consider the correlations between partners' SRR scores in the dyadic datasets to tap into something akin to inter-rater reliability. Heterosexual male and female partners' SRR scores were positively associated $(r=.31, p<.01)$. See also online supplementary materials.

Second, self-disclosure may relate to a sense of shared reality not only via actor effects (i.e., associations within the same persons), but also via partner effects (i.e., one partner's disclosure strengthens the other partner's sense of shared reality). We treat such correspondence 
as a form of convergent validity. Accordingly, we tested a simple Actor-Partner Interdependence Model (APIM; Kenny et al., 2006) among opposite-sex couples (who had a reasonably large sample size), with male and female partners' self-disclosure as predictors and both partners' SRR scores as outcomes in a manifest-variable path model. Actor effects from the same person's selfdisclosure to SRR were significant (men's standardized $\beta=.34, p<.001$; women's $\beta=.26, p<$ .05). In addition, one partner effect, from women's self-disclosure to men's sense of shared reality regarding the relationship, was significant $(\beta=.45, p<.001)$. The model was saturated, so goodness-of-fit statistics were not informative.

Finally, using the individuals' sample (the largest one), we examined the generality of results across the university announcement-system $(n=67)$ and MTurk $(n=244)$ subsamples via a multiple-group, manifest-variable model. This model assessed 22 correlations of interest among eight major study variables. Details are provided in the online supplement, but the main conclusion was that the pattern of correlations among the major variables generalized well across the university- and MTurk-based subsamples. Cross-sample constraints could be maintained on 15 of the 22 correlations, and differences between the other seven correlations tended to be modest in magnitude.

\section{Discussion}

Our findings support the reliability and validity of the Shared Reality regarding one's Relationship (SRR) scale. Its alpha reliability coefficients were in or around the .80s in our larger datasets, and the composite reliability in the overall individuals' dataset was similar. The moderate between-partner correlations we obtained with the SRR measure (significant in opposite-sex couples) also suggests some degree of inter-rater-type reliability in how partners perceive their shared reality, although strictly speaking, objective congruence is not required 
(Echterhoff et al., 2009; Pinel et al., 2015). Further, the SRR measure showed concurrentvalidity with its two most kindred constructs (general couples' shared reality and existential connection), but the SRR's correlations with these constructs were not excessive, according to tests with the average variance extracted. The SRR also showed good criterion-related validity with relationship satisfaction and disillusionment. However, it showed only mixed convergent validity with constructs thought to be conducive to a sense of shared reality. SRR was well-correlated with self-disclosure, not merely as an actor effect, but also as a partner effect from women's selfdisclosure to men's sense of shared reality regarding one's relationship. The SRR also correlated consistently with the IOS. The SRR did not, however, correlate strongly with empathetic concern and perspective-taking, even in actor effects (general couples' shared reality and existential connection did not either). Empathic concern and perspective-taking assess individual characteristics and abilities, whereas the sense of shared reality is a feeling of closeness that can be found in any romantic relationship, regardless of partners' skills. These findings fail to support Echterhoff et al.'s (2009) theoretical assumption claiming perspective-taking and empathy to be building blocks for shared reality.

Another scale used for concurrent-validity purposes, couples' general shared reality, was highly correlated with our SRR. However, a comparison of these two scales' relations with other scales shows stronger evidence for the SRR than the couples' general shared-reality instrument as a correlate of self-disclosure, relationship satisfaction, and romantic disillusionment. Ultimately, we see the SRR and couples' general shared-reality scales as partially overlapping constructs, which nevertheless leave room for each to address unique niches of relationshiptargeted and general shared reality between romantic partners, respectively. 
As predicted, the SRR was significantly correlated with criterion-validity scales assessing relationship satisfaction and disillusionment. Those who had a higher sense of shared reality with their partner regarding their relationship were more satisfied in their relationship and felt less disillusioned.

\section{Study 2 (Test-Retest Reliability and Other Analyses)}

We conducted Study 2 primarily to obtain test-retest reliability for the SRR. We also sought a sample independent from Study 1's to conduct a Confirmatory Factor Analysis (CFA) on the SRR. Finally, Study 2 examined one additional variable, interpersonal responsiveness (Reis et al. 2011), for convergent validity with the SRR (IOS and disillusionment were also administered in Study 2 and thus available for testing convergent and criterion-related validity, respectively, with the SRR).

\section{Methods}

Samples and procedures. Researchers visited undergraduate classrooms at the same university used in Study 1, to invite students to participate in a brief two-part online (Qualtrics) survey about romantic relationships. All students were eligible, as they were allowed to complete the measures regarding a current ongoing relationship, a previous relationship, or a future relationship they envisioned. Students in these classes received follow-up e-mails including a link on which they could click to access the survey. Approximately two weeks after the initial administration of the online survey, the researchers sent e-mails to the classes alerting students to complete the second phase. Fifty-eight students completed both phases of the test-retest study. A total of 154 students completed Phase 1 (96 Phase- 1 only plus 58 at both phases) and a total of 119 completed Phase 2 (61 Phase-2 only plus 58 at both phases). Among individuals who participated in at least one phase (and excluding those who had missing data on these 
demographic items), 90\% were female; $66 \%$ were White, 20\% were Hispanic, $6 \%$ were AfricanAmerican and the rest were multiracial or other; and 59\% completed the survey with regard to a current actual romantic relationship, $26 \%$ with regard to a previous actual relationship, and 15\% with regard to a future hypothetical relationship they envisioned.

Measures. Three of the measures used in Study 2 - the SRR, Inclusion of Other in the Self, and romantic disillusionment - were the same as in Study 1. One newly introduced measure was that of interpersonal responsiveness (Reis et al., 2011). The responsiveness measure contained 12 items (e.g., "My partner sees the 'real' me," "My partner esteems me, shortcomings and all," and "My partner really listens to me"), with responses on a scale from 1 (not at all true) to 7 (completely true). One item, "My partner is on 'the same wavelength' with me," raised concern over content overlap with shared reality. However, results were virtually indistinguishable with and without this item, so it was retained. Alpha reliability levels were .96 and .97 at Phases 1 and 2, respectively.

\section{Results}

Test-retest, alpha, and composite reliability. Test-retest reliability for the SRR over a roughly two-three week interval was $r=.71(p<.001)$. Alphas for the SRR were .90 and .88 at Phases 1 and 2. Composite reliability was .87 at each phase.

Confirmatory factor analysis. To cross-validate the exploratory factor structure of the SRR in Study 1 (i.e., one factor amidst other factors for couples' general shared reality and existential connection), we conducted a CFA on just the five SRR items in Study 2, positing them as indicators of a single SRR factor. Participants available at Phase $1(N=154)$ were included in the CFA, using the SRR administered at Phase 1. The CFA was conducted with AMOS 25 (Arbuckle, 2017). Standardized item loadings were strong, ranging from .74-.85. Two 
items correlated especially highly, presumably because the wording of each referenced an interaction with the partner (the partner talking to the respondent or conveying a message through his or her behavior) as leading to the sense of shared reality regarding the relationship. The residuals for these items were thus allowed to correlate $(r=.47, p<.001)$. Most of the conventional fit indices of this model were strong (Comparative Fit Index $=.96$, Tucker-Lewis Index $=.91$, Normed Fit Index $=.96$ ), although an exception was the Root Mean Square Error of Approximation (.18).

Convergent and criterion-related validity. SRR correlated highly with responsiveness at Phases $1(r=.82)$ and $2(r=.72)$. SRR also correlated highly with disillusionment at the two phases $\left(r^{\prime} \mathrm{s}=-.81\right.$ and -.76$)$ and moderately with the $\operatorname{IOS}\left(r^{\prime} \mathrm{s}=.47\right.$ and .38 ; all $p$ 's $\left.<.001\right){ }^{2}$

Discriminant validity. Discriminant validity in the sense of whether two conceptually and empirically associated measures were distinct - with a focus on SRR and responsiveness -was again examined via average variance extracted and squared correlations. In Phase 1, the squared correlation between SRR and responsiveness was .67. AVE for SRR (.57) and responsiveness (.47) were below the $r^{2}$, hence SRR and responsiveness could not be considered distinct at Phase 1. However, at Phase 2, the AVE for both SRR (.58) and responsiveness (.61) both exceeded the $r^{2}$ between the variables (.52), supporting the idea that SRR and responsiveness were distinct constructs.

\section{Discussion}

The Shared Reality regarding one's Relationship (SRR) measure exhibited high testretest reliability over a two-three week period. Some concern arose over the SRR's distinguishability from Reis and colleagues' (2011) responsiveness construct. Only at one of the two phases (Phase 2) did analyses of average variance extracted and squared correlations support 
the distinguishability of SRR and responsiveness. The SRR also correlated negatively with disillusionment at a higher magnitude than in Study 1, and correlated positively the IOS at a similar magnitude as in Study 1.

\section{General Discussion}

Results of the two studies largely supported the psychometric quality of the Shared Reality regarding one's Relationship (SRR) measure. Its test-retest, internal consistency (alpha), and composite reliability values were strong. So, for the most part, were its concurrent, convergent, discriminant, and criterion-related validity. A finding of concern, obtained in one phase of Study 2 but not the other phase, was the large correlation between the SRR and Reis and colleagues' (2011) responsiveness measure. We were surprised at this heavy empirical overlap, as the SRR taps only into perceived cognitive congruity about one's relationship (i.e., sharing the same story of the relationship's history, and agreeing on the relationship's stage, goals, and values), whereas the responsiveness measure encompasses not only similar cognitive aspects (being on the same wavelength), but also affective (feeling esteemed and liked by the partner) and behavioral (believing the partner "really listens to me") features. Pending further study into why the SRR and responsiveness constructs may correlate so highly, we would urge researchers to select measures based on conceptual grounds, namely whether they are interested more in specific cognitive congruity between partners (which would suggest use of the SRR) or an overall sense of partners being attuned to each other (suggesting use of the responsiveness scale). Alternatively, researchers so inclined may even wish to investigate a higher-order sharedreality "super-construct" in structural equation modeling, with the SRR, the couples' general shared- reality measure, the modified couple-focused Existential Isolation Scale, and the responsiveness scale as lower-order constructs. 
As noted above, part of Echterhoff and colleagues' (2009) conceptualization of perceived shared reality is that it stems from either relational or epistemic motives. The SRR's item content predominantly reflects relational motives, alluding to relationship goals and relationship values, for example (Table 2). One item, however, alludes to feeling more understood when one's partner confirms agreement on some relationship issue. Wanting to understand one's partner and feel understood by him or her captures an epistemic motivation. Further, Rossignac-Milon and Higgins (2018) argue that the epistemic aspect of perceived shared reality, "making sense of the world together" (p. 66), brings partners together. The SRR's significant positive correlations with Inclusion of Other in the Self and relationship satisfaction, and negative association with disillusionment, across samples support this suggestion. One concern some may have is that the "feeling more understood" item is different from the other four items' direct declarations that "My partner and I share..." and "My partner and I agree..." Although the item on feeling understood arguably diminishes the SRR's conceptual uniformity somewhat, the SRR remains empirically cohesive and the item's epistemic content is a strength.

Findings from a completely separate study in our lab (names redacted) link the SRR to perceived and actual match between oneself and one's partner on relationship-relevant attitudes (how acceptable/unacceptable one considers behaviors such as keeping elements of one's past secret from one's partner or flirting over the Internet with someone other than one's partner), further supporting the epistemic relevance of the SRR. Both members of dating couples independently rated their own sense of acceptability of the listed behaviors, then indicated how they thought their partner would answer. This procedure yielded three measures: the couple's actual agreement (absolute difference between the two partners' own attitudes), each partner's perceived agreement (absolute difference of the same person's own and predicted partner 
attitude), and each partner's predictive accuracy (absolute difference between one partner's prediction for the other partner and the other partner's own attitude). Higher men's SRR (but not women's) was significantly associated with greater match (smaller absolute differences) in the domains of actual agreement, perceived agreement, and accuracy. Follow-up comparisons showed that, whereas the men's correlations surpassed the threshold for statistical significance and women's did not, the magnitude of the men's correlations was not significantly larger than those of the women.

Some may question why researchers could not modify item wordings within the couples' general shared reality scale to pinpoint relationship-specific matters, instead of a new instrument such as the SRR being required. We agree that some couples' general shared-reality items could be modified by inserting the phrase "about our relationship," but not all of them. For example, the hypothetical modified general item "We frequently think of things about our relationship at the exact same time" would seem awkward. Further, we went to great pains to incorporate Echterhoff et al.'s (2009) four theoretical criteria for perceived shared reality (i.e., a common inner state, pertaining to the relationship, inspired by relational motives, and no contradiction). For researchers to modify another instrument such as the couples' general shared-reality scale and still maintain fidelity to Echterhoff and colleagues' criteria could disrupt the conceptual underpinnings.

Research and theory reviewed above suggest several possible mechanisms for how a sense of shared reality regarding one's relationship can promote better relationship quality: through confidence in one's choice of partner, a sense of feeling understood by one's partner, fulfillment of basic psychological needs, and language use indicative of connection such as "we" references (Niehuis et al., 2018; Philippe et al., 2013; Rossignac-Milon \& Higgins, 2018; Wilson 
\& Huston, 2013). Based on these findings, shared reality regarding one's relationship can be hypothesized as a predictor of relationship outcome in future - ideally longitudinal - studies, with many possible mediational pathways to investigate.

Our findings have possible practical applications, as well, namely for the counseling of couples. Pinel and colleagues have written extensively on psychotherapeutic applications of Isharing, a construct similar to shared reality. Pinel et al. (2015) described a study from their lab in which each partner from cohabitating couples undertook a separate I-sharing exercise with a stranger, before being reunited to discuss a challenging topic in their relationship. Compared to control couples who did not receive the I-sharing activity, those who did showed a longer-lasting ability to compromise. Relatedly, a dissertation study from Pinel's lab (Huneke, 2017) has introduced a new intervention to increase I-sharing. Though some of Pinel et al.'s (2015) discussion centers around I-sharing between a therapist and individual client, these authors note that, "Work on the relationship-building consequences of I-sharing also suggests that therapists working with couples and/or families might want to concentrate their energy on how to help the people involved increase their moments of I-sharing" (p. 65). Studies evaluating the effectiveness of I-sharing interventions over time could repeatedly administer the SRR, as well as the couples' general shared-reality and existential-isolation measures, to track couples' progress. Although we have shown the SRR to have strong test-retest reliability, individuals' scores may change when receiving an intervention designed to affect the domain being measured (i.e., one's marriage/relationship).

Like all studies, ours had limitations. Even though we assessed many possible kindred constructs to the SRR, we did not include all possible similar measures. For example, we did not include Ivanov and Werner's (2018) Perceptual Agreement Questionnaire, which came out after 
we began our main study. Though the latter instrument taps into partners' agreement in some items ("We agree on how satisfied [or not satisfied] we feel in our relationship"), other items appear to assess partners' understanding of each other rather than agreement ("Even if we disagree, we generally understand each other's point of view"). Also, because Study 1 had focal respondents invite their partner to participate, there may be some selection bias. Research has found higher relationship quality in focal individuals who successfully recruit their partner into a study than in those whose partners decline (Barton, Lavner, Stanley, Johnson, \& Rhoades, 2020). Despite any self-selection issues, however, many of the validity coefficients (Table 3) were similar in the individual (where partners declined to participate) and couple samples. ${ }^{3}$

Overall, in our view, the study's limitations are far outweighed by its strengths. These include the use of dyadic data for a subset of participants, diversity in couples' sexual and gender orientations and identities, a longitudinal study to obtain test-retest reliability, and exploratory and confirmatory factor analyses of the SRR in separate samples. Further, the largely invariant solution we obtained between the university-based and national MTurk samples suggests that the applicability of the SRR is not confined to any one participant population. In conclusion, the Shared Reality regarding one's Relationship scale has shown good initial reliability and validity, fits within a conceptual nexus of studies on couples' subjective and objective shared relationship memories, and potentially can be used in clinical settings. 


\section{References}

Alea, N., \& Vick, S. C. (2010). The first sight of love: Relationship-defining memories and marital satisfaction across adulthood. Memory, 18, 730-742. doi:

$10.1080 / 09658211.2010 .506443$

Arbuckle, J. L. (2017). IBM SPSS Amos 25 user's guide. Crawfordville, FL: Amos Development Corporation.

Aron, A., Aron, E. N., \& Smollan, D. (1992). Inclusion of other in the self scale and the structure of interpersonal closeness. Journal of Personality and Social Psychology, 63(4), 596-612. doi: $10.1037 / 0022-3514.63 .4 .596$

Barton, A. W., Lavner, J. A., Stanley, S. M., Johnson, M. D., \& Rhoades, G. K. (2020). “Will you complete this survey too?" Differences between individual versus dyadic samples in relationship research. Journal of Family Psychology, 34, 196-203. doi:

10.1037/fam0000583

Berger, P., \& Kellner, H. (1964). Marriage and the construction of reality: An exercise in the microsociology of knowledge. Diogenes, 12, 1-24. doi: 10.1177/039219216401204601

Berger, P. L., \& Luckmann, T. (1967). The social construction of reality: A treatise in the sociology of knowledge. Harmondsworth, UK: Penguin (Original: Garden City, NY: Doubleday, 1966).

Buhrmester, M. D., Kwang, T., \& Gosling, S. D. (2011). Amazon's mechanical Turk: a new source of inexpensive, yet high quality data. Perspectives on Psychological Science, 6, 35. doi: 10.1177/1745691610393980 
Chadiha, L. A., Veroff, J., \& Leber, D. (1998). Newlywed's narrative themes: Meaning in the first year of marriage for African American and White couples. Journal of Comparative Family Studies, 29, 115-130.

Cheung, G. W., \& Wang, C. (2017). Current approaches for assessing convergent and discriminant validity with SEM: Issues and solutions (abstract only). Academy of Management Proceedings. 2017 (1). doi: 10.5465/AMBPP.2017.12706abstract

Davis, M. H. (1980). A multidimensional approach to individual differences in empathy. JSAS Catalog of Selected Documents in Psychology, 10, 85-104. Retrieved from https://www.uv.es/ friasnav/Davis_1980.pdf

Echterhoff, G., Higgins, E. T., \& Levine, J. M. (2009). Shared reality: Experiencing commonality with others' inner states about the world. Perspectives on Psychological Science, 4, 496-521. doi: 10.1111/j.1745-6924.2009.01161.x

Echterhoff, G., Kopietz, R., \& Higgins, E. T. (2017). Shared reality in intergroup communication: Increasing the epistemic authority of an out-group audience. Journal of Experimental Psychology: General, 146, 806-825. doi: 10.1037/xge0000289

Fornell, C., \& Larcker, D. F. (1981). Evaluating structural equation models with unobservable variables and measurement error. Journal of Marketing Research, 18, 39-50.

Gilet, A.-L., Mella, N., Studer, J., Grühn, D., \& Labouvie-Vief, G. (2013). Assessing dispositional empathy in adults: A French validation of the Interpersonal Reactivity Index (IRI). Canadian Journal of Behavioural Science/Revue Canadienne des Sciences du Comportement, 45, 42-48. doi: 10.1037/a0030425 
Godwin, M., Pike, A., Bethune, C., Kirby, A., \& Pike, A. (2013). Concurrent and convergent validity of the Simple Lifestyle Indicator Questionnaire. ISRN Family Medicine, Online article no. 529645. doi: 10.5402/2013/529645

Gomillion, S., Gabriel, S., Kawakami, K., \& Young, A. F. (2017). Let's stay home and watch TV: The benefits of shared media use for close relationships. Journal of Social and Personal Relationships, 34, 855-874. doi: 10.1177/0265407516660388_

Harris, S. M., Glenn, N. D, Rappleyea, D. L., Diaz-Loving, R., Hawkins, A. J., Daire, A. P., Osborne, C., \& Huston, T. L. (2008). Twogether in Texas: Baseline report on marriage in the Lone Star State. Austin, TX: Health and Human Services Commission. Retrieved from: https://twogetherintexas.com/pdf/baselinereport.pdf

Havey, J. M., Story, N., \& Buker, K. (2002). Convergent and concurrent validity of two measures of phonological processing. Psychology in the Schools, 39, 507-514. doi: 10.1002/pits. 10056

Holmberg, D. , Orbuch, T. , \& Veroff, J. (2004). Thrice-told tales. Married couples tell their stories. Mahwah, NJ: Erlbaum.

Huneke, M. (2017). Making I-contact: Fostering shared, in-the-moment subjective experiences. Doctoral dissertation, University of Vermont. Retrieved from:

\section{https://scholarworks.uvm.edu/graddis/729}

Huston, T. L., Niehuis, S., \& Smith, S. E. (2000). Courtship and the newlywed years: What they tell us about the future of a marriage. Revista de Psicologia Social y Personalidad, 16(2), $155-178$.

Huston, T. L., Niehuis, S., \& Smith, S. E. (2001). The early marital roots of conjugal distress and divorce. Current Directions in Psychological Science, 10(4), 116-119. 
IBM Support (2018). Difference between alpha and alpha for standardized items in Reliability output [Document 420533]. Armonk, NY: IBM Corp. Retrieved from https://www.ibm.com/support/pages/difference-between-alpha-and-alpha-standardizeditems-reliability-output

Ivanov, M., \& Werner, P. D. (2018). Perceptual agreement: Assessing reality and illusion in romantic relationships. Couple and Family Psychology: Research and Practice, 7, 76-90. doi: $10.1037 / \mathrm{cfp} 0000101$

Joel, S., Eastwick, P. W., Allison, C. J., Arriaga, X. B., Baker, Z. G., Bar-Kalifa, E., Bergeron, S., Birnbaum, G., Brock, R. L., Brumbaugh, C. C., Carmichael, C. L., Chen, S., Clarke, J., Cobb, R. J., Coolsen, M. K., Davis, J., de Jong, D. C., Debrot, A., DeHaas, E. C.... Wolf, S. (in press). Machine learning uncovers the most robust self-report predictors of relationship quality across 43 longitudinal couples studies. Proceedings of the National Academy of Sciences.

Kenny, D. A., Kashy, D. A., \& Cook, W. L. (2006). Dyadic data analysis. New York, NY: Guilford Press.

Knight, G. P., Gonzales, N. A., Saenz, D. S., Bonds, D., German, M., Deardorff, J., Roosa, M. W., \& Updegraff, K. A. (2010). The Mexican American Cultural Values Scale for adolescents and adults. Journal of Early Adolescence, 30, 444-481. doi: $10.1177 / 0272431609338178$

Lee, K.-H., Swenson, A., \& Niehuis, S. (2010). His or her parents? Perceived parental approval of romantic relationships among college students and their partners. Interpersona: An International Journal on Personal Relationships, 4(2), 213-236. doi: 10.5964/ijpr.v4i2.50 
Mahmood, J., Dahlan, H. M., Hussin, A. R. C., \& Ahmad, M. A. (2018). Development and validation of instrument for assessing researcher's participation in e-collaboration. In F. Saeed, N. Gazem, F. Mohammed, \& A. Busalim (Eds.), Recent trends in data science and soft computing (pp. 1066-1076 ). Cham, Switzerland: Springer Nature. doi: 10.1007/978-3-319-99007-1_99

Mashek, D., Le, B., Israel, K., \& Aron, A. (2011). Wanting less closeness in romantic relationships. Basic and Applied Social Psychology, 33, 333-345. doi: $10.1080 / 01973533.2011 .614164$

Niehuis, S. (2006). Organization of partner knowledge, its effect on passion, and the mediating effect of idealization. North American Journal of Psychology, 8, 33-46.

Niehuis, S. (2007). Convergent and discriminant validity of the Marital Disillusionment Scale. Psychological Reports, 100(1), 203-207. doi: 10.2466/PR0.100.1.203-207

Niehuis, S., Huston, T. L., \& Rosenband, R. (2006). From courtship to marriage: A new developmental model and methodological critique. Journal of Family Communication, 6, 23-47. doi: 10.1207/s15327698jfc0601_3

Niehuis, S., Lee, K.-H., Reifman, A., Swenson, A., \& Hunsaker, S. (2011). Idealization and disillusionment in intimate relationships: A review of theory, method, and research. Journal of Family Theory \& Review, 3, 273-302. doi: 10.1111/j.1756-2589.2011.00100.x

Niehuis, S., Ogolsky, B., Reifman, A., Oldham, R., \& Ireland, M. (2018, July). On the same wavelength? Agreement in partners' marriage-commitment trajectories as a key element in relationship functioning. Presentation at the International Association for Relationship Research conference, Fort Collins, Colorado. 
Niehuis, S., Reifman, A., Al-Khalil, K., Oldham, C. R., Fang, D., O’Boyle, M., \& Davis, T. H. (2019). Functional magnetic resonance imaging activation in response to prompts of romantically disillusioning events. Personal Relationships, 26, 209-231. doi:

$10.1111 /$ pere. 12272

Niehuis, S., Reifman, A., Feng, D., \& Huston, T. L. (2016). Courtship progression rate and declines in expressed affection early in marriage. Journal of Family Issues, 37, 10741100. doi: $10.1177 / 0192513 X 14540159$

Niehuis, S., Reifman, A. S., Fischer, J. L., \& Lee, K.-H. (2016). Do episodic self- and partneruncertainty mediate the association between attachment orientations and emotional responses to relationship-threatening events in dating couples? Cognition and Emotion, 30, 1232-1245. doi: 10.1080/02699931.2015.1050999

Niehuis, S., Reifman, A., \& Lee, K.-H. (2015). Disillusionment in cohabiting and married couples: A national study. Journal of Family Issues, 36, 951-973. doi:

\section{$10.1177 / 0192513 X 13498594$}

Niehuis, S., Reifman, A., \& Oldham, C. R. (2019). Effects of relationship transgressions on idealization of and disillusionment with one's romantic partner: A three-wave longitudinal study. Personal Relationships, 26, 466-489. doi: 10.1111/pere.12287

Niehuis, S., Reifman, A., Weiser, D., Punyanunt-Carter, N., Flora, J., Arias, V. S., \& Oldham, C. R. (2020). Guilty pleasure? Communicating sexually explicit content on dating-apps and disillusionment with app usage. Human Communication Research, 46, 563-593. doi: 10.1093/hcr/hqz013

Niehuis, S., Skogrand, L., \& Huston, T. L. (2006). When marriages die: Premarital and early marital precursors to divorce. The Forum for Family and Consumer Issues, 11(1), 1-7. 
Ogolsky, B., Niehuis, S., \& Ridley, C. (2009). Using online methods and designs to conduct research on personal relationships. Marriage and Family Review, 45(6), 610-628. doi: $10.1080 / 01494920903224202$

Parks, M. R., \& Floyd, K. (1996). Making friends in cyberspace. Journal of Computer-Mediated Communication, 46, 80-97. doi: 10.1111/j.1460-2466.1996.tb01462.x

Péloquin, K., \& Lafontaine, M. F. (2010). Measuring empathy in couples: Validity and reliability of the Interpersonal Reactivity Index for couples. Journal of Personality Assessment, 92, 146-157. doi: 10.1080/00223890903510399

Philippe, F. L., Koestner, R., \& Lekes, N. (2013). On the directive function of episodic memories in people's lives: A look at romantic relationships. Journal of Personality and Social Psychology, 104, 164-179. doi: 10.1037/a0030384164

Pinel, E. C., Bernecker, S. L., \& Rampy, N. (2015). I-sharing on the couch: On the clinical implications of shared subjective experience. Journal of Psychotherapy Integration, 25, 59-70. doi: 10.1037/a0038895

Pinel, E. C., Long, A. E., Murdoch, E. Q., \& Helm, P. (2017). A prisoner of one's own mind: Identifying and understanding existential isolation. Personality and Individual Differences, 105, 54-63. doi: 10.1016/j.paid.2016.09.024

Reifman, A., \& Niehuis, S. (2018). Over- and under-perceiving social support from one's partner and relationship quality over time. Marriage and Family Review, 54(8), 793-805. doi: $10.1080 / 01494929.2018 .1501632$ 
Reifman, A., Ursua-Benitez, M., Niehuis, S., Willis-Grossmann, E., \& Thacker, M. (2020). \#HappyAnniversary: Gender and age differences in spouses' and partners' Twitter greetings. Interpersona: An International Journal on Personal Relationships, 14, 54-68.

Reis, H. T., Maniaci, M. R., Caprariello, P. A., Eastwick, P. W., \& Finkel, E. J. (2011). Familiarity does indeed lead to attraction in live interaction. Journal of Personality and Social Psychology, 101, 557-570. doi: 10.1037/a0022885

Rossignac-Milon M., Bolger N., \& Higgins E. T. (2016, July). Shared reality increases explicit and implicit interpersonal closeness in romantic and unacquainted dyads. Presented at the International Association for Relationship Research conference, Toronto, Ontario, Canada.

Rossignac-Milon, M., \& Higgins, E. T. (2018). Epistemic companions: Shared reality development in close relationships. Current Opinion in Psychology, 23, 66-71. doi: 10.1016/j.copsyc.2018.01.001

Suhartanto, D., Ruhadi, N., \& Triyuni, N. N. (2016). Tourist loyalty toward shopping destination: The role of shopping satisfaction and destination image. European Journal of Tourism Research, 13, 84-102.

Widhiarsoa, W., \& Kožený, J. (2013). Applying confirmatory factor analysis to evaluate the fit of measurement models in education and psychological assessment. Journal of Educational Sciences and Psychology, 3, 78-88.

Wilson, A. C., \& Huston, T. L. (2013). Shared reality and grounded feelings during courtship: Do they matter for marital success? Journal of Marriage and Family, 75(3), 681-696. doi: 10.1111/jomf.12031 
Wood, W. I., Oldham, C. R., Reifman, A., \& Niehuis, S. (2017). Accuracy and bias in newlywed spouses' perceptions of each other's personalities. Personal Relationships, 24, 886-901. doi: $10.1111 /$ pere. 12219 
Table 1

Variables Used to Test Different Forms of Validity for Shared Reality regarding one's Relationship scale (SRR)

\begin{tabular}{lll}
\hline & $\underline{\text { Study } 1}$ & Study 2 \\
\hline Concurrent & $\bullet$ & $\bullet$ \\
Couples' General Shared Reality & $\bullet$ & $\bullet$ \\
Existential Connection & $\bullet$ \\
\hline Convergent & $\bullet$ \\
Self-Disclosure & $\bullet$ \\
Inclusion of Other in the Self & \\
Empathic Concern & $\bullet$ \\
Perspective-Taking & $\bullet$ \\
Responsiveness & $\bullet$ \\
\hline Criterion-Related & $\bullet$ \\
Relationship Satisfaction (MOQ) & \\
\hline Discriminant (No Correlation Expected) & \\
\hline Familism &
\end{tabular}

Note. $\mathrm{MOQ}=$ Marital Opinion Questionnaire modified to also include unmarried couples. 
Table 2

Exploratory Principal Components Analysis of Shared Reality regarding one's Relationship scale (SRR), Couples' General Shared Reality, and Existential Connection Items (Study 1,

Individuals' Dataset, $N=356$ )

\begin{tabular}{|c|c|c|c|}
\hline & $\begin{array}{l}\text { Comp. } 1 \\
\text { SRR }\end{array}$ & $\begin{array}{l}\text { Comp. } 2 \\
\text { General } \\
\text { Shared } \\
\text { Reality }\end{array}$ & $\begin{array}{l}\text { Comp. } 3 \\
\text { Existential } \\
\text { Connect }^{\mathrm{a}}\end{array}$ \\
\hline \multicolumn{4}{|l|}{ Shared Reality regarding one's Relationship scale } \\
\hline $\begin{array}{l}\text { My partner and I share the same story as to how we got to where we } \\
\text { are in our relationship now and we feel the same way about it. }\end{array}$ & .70 & .15 & .28 \\
\hline $\begin{array}{l}\text { My partner and I agree on what stage of our relationship we are in } \\
\text { right now. }\end{array}$ & .82 & .26 & .17 \\
\hline $\begin{array}{l}\text { When my partner talked to me about his/her plans for the future, I } \\
\text { realized that we are on the same page regarding our relationship } \\
\text { goals. }\end{array}$ & .79 & .22 & .21 \\
\hline $\begin{array}{l}\text { Based on my partner's behaviors, I know we share the same } \\
\text { relationship values. }\end{array}$ & .78 & .24 & .31 \\
\hline $\begin{array}{l}\text { I feel more understood when my partner confirms that he/she sees } \\
\text { an issue in our relationship the same way I do. }\end{array}$ & .59 & .46 & .11 \\
\hline \multicolumn{4}{|l|}{ Couples' General Shared Reality Items } \\
\hline We frequently think of things at the exact same time. & .21 & .59 & .46 \\
\hline Through our discussions, we often develop a joint perspective. & .46 & .58 & .34 \\
\hline We typically share the same thoughts and feelings about things. & .31 & .45 & .61 \\
\hline Events feel more real when we experience them together. & .48 & .62 & .09 \\
\hline The way we think has become more similar over time. & .38 & .63 & .32 \\
\hline We often anticipate what the other is about to say. & .15 & .68 & .33 \\
\hline $\begin{array}{l}\text { We are more certain of the way we perceive things when we are } \\
\text { together. }\end{array}$ & .25 & .78 & .18 \\
\hline We often feel like we have created our own reality. & .07 & .74 & .08 \\
\hline \multicolumn{4}{|l|}{ Existential Connection Items } \\
\hline I usually feel that my partner and I share the same outlook on life. & .72 & .17 & .45 \\
\hline I often have the same reaction to things that my partner does. & .30 & .14 & .77 \\
\hline $\begin{array}{l}\text { I do not feel lonely most of the time because my partner } \\
\text { understands my experiences. }\end{array}$ & .49 & .19 & .57 \\
\hline My partner has the same take or perspective on things that I do. & .29 & .19 & .80 \\
\hline $\begin{array}{l}\text { My partner and I react to things in our environment in the same } \\
\text { way. }\end{array}$ & .12 & .29 & .78 \\
\hline \multicolumn{4}{|c|}{ Psychometrics for Unit-Weighted Scales Based on Each Component (Men and Women Combined) } \\
\hline Alpha Reliability & .88 & .89 & .87 \\
\hline Composite Reliability & .86 & .84 & .81 \\
\hline Average Variance Extracted & .55 & .41 & .48 \\
\hline Correlation (and $r^{2}$ ) with Couples' General Shared Reality & $.69(.48)$ & --- & --- \\
\hline Correlation (and $r^{2}$ ) with Existential Connection & $.70(.49)$ & $.69(.48)$ & --- \\
\hline
\end{tabular}

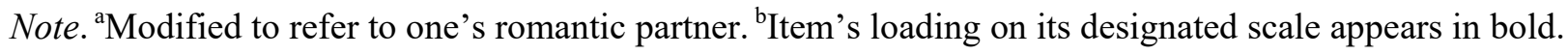


Table 3

Correlations between Shared-Reality and Other Constructs (Study 1)

\begin{tabular}{|c|c|c|c|}
\hline & $\begin{array}{c}\text { Shared Reality regarding one's } \\
\text { Relationship scale (SRR) }\end{array}$ & $\begin{array}{l}\text { Couples' General } \\
\text { Shared Reality }\end{array}$ & Existential Connection \\
\hline Couples' General Shared Reality & $.76 / .65 / .24 / .60$ & --- & --- \\
\hline Existential Connection & $.79 / .66 / .48 / .62$ & $.73 / .66 / .43 / .71$ & --- \\
\hline Perspective-Taking & $.09 / .23 / .11 /-.02$ & $. \mathbf{3 0} / . \mathbf{1 5} / .17 / .05$ & $.20 / .19 / .07 /-.01$ \\
\hline Empathic Concern & $.32 / .22 / .17 /-.06$ & $.32 / .11 / .27 / .11$ & $.32 / .11 / .24 / .03$ \\
\hline Self-Disclosure & $.34 / .41 / .46 / .17$ & $.16 / .33 / .08 / .02 /$ & $.23 / .26 / .14 /-.02$ \\
\hline Inclusion of Other in Self & $.43 / .31 / .43 / .25$ & $.34 / .41 / .33 / .18$ & $. \mathbf{4 2} / . \mathbf{3 7} / . \mathbf{3 7} / .21$ \\
\hline Relationship Satisfaction & $. \mathbf{4 0} / . \mathbf{4 6} / . \mathbf{4 8} / .20$ & $. \mathbf{3 4} / . \mathbf{4 5} / .12 / .09$ & $.48 / .46 / .51 / .19$ \\
\hline Romantic Disillusionment & $-.40 /-.47 /-.55 /-.27$ & $-.26 /-.45 /-.10 /-.18 /$ & $-.38 /-.44 /-.47 /-.20$ \\
\hline
\end{tabular}

Note. Each set of correlations for a pair of variables is presented in this order: men in individual sample/women in individual sample/men in opposite-sex couple sample/women in opposite-sex couple sample. Correlations in bold font were significant $(p \leq .05)$. 


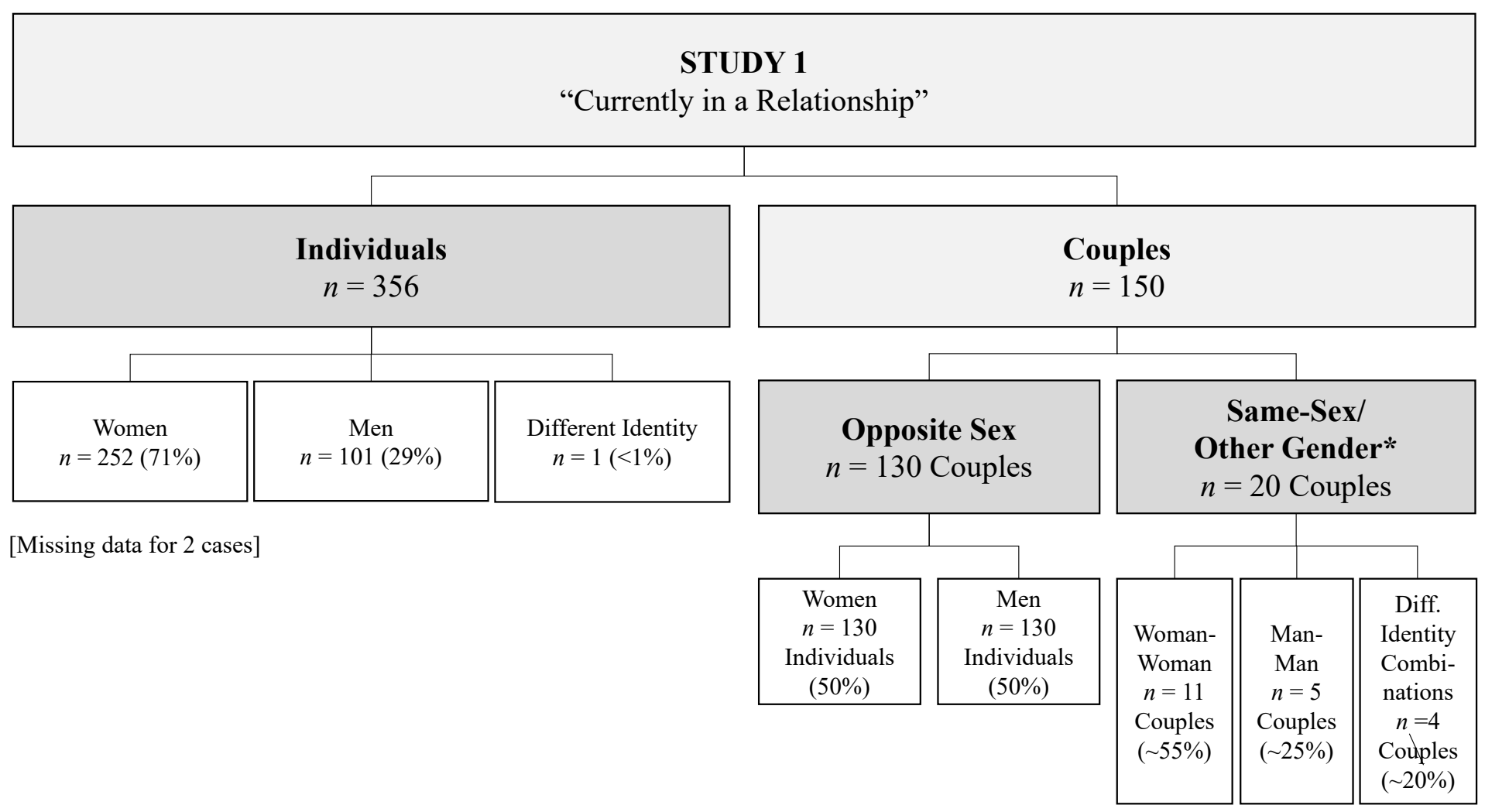

Figure 1. Schematic of samples in Study 1. (*Results for same-sex/other gender couples are presented in supplemental online materials.) 


\section{Endnotes}

${ }^{1}$ The distinction between concurrent and convergent validity is not clear-cut. Many sources use the two relatively interchangeably, plus there is no unanimity on the definition for either term alone. Several articles do, however, offer themes that distinguish the two. Godwin, Pike, Bethune, Kirby, and Pike (2013) state that "Concurrent validity is determined by comparing the score on the instrument of interest... with the score on a reference standard - a measurement tool that is known to accurately measure that same construct." Havey, Story, and Buker (2002) describe concurrent validity simply as correlating a focal instrument with "other measures" of the same construct (p. 509). In contrast, Madowitz et al. (2014) define convergent validity in terms of "correlation between [a focal instrument's] scores and the scores of another measure that assesses a different but theoretically similar construct" (p. 288). In short, whereas concurrent validity involves correlating a focal instrument with another instrument as similar as possible to the focal one, convergent validity allows the focal instrument to be correlated with a construct that is recognized as being at least somewhat different.

${ }^{2}$ The two-week longitudinal design allowed for possible tests of predictive validity in the form of associations between Phase-1 SRR and Phase-2 outcomes (e.g., disillusionment), controlling for Phase-1 versions of the outcome. Such tests are very conservative in general, and combined with the short interval between assessments (yielding high autocorrelation of variables) and relatively small sample size, such predictive analyses were not significant.

${ }^{3}$ For example, the SRR-couples' general shared reality correlations in women were $r$ individual $=.65$ and $r$ couple $=.60$; the SRR-existential connection correlations in women were were $r$ individual $=.66$ and $r_{\text {couple }}=.62$; and the SRR-IOS correlations in men were $r=.43$ in both the individual and couple samples. 